\title{
Nanotechnology, Governance and Public Management: A Techno-Economic Paradigms Perspective
}

Wolfgang Drechsler

\begin{abstract}
This essay investigates, from the perspective of Carlota Perez' theory of TechnoEconomic Paradigms, the possible impact of a specific technology, nanotechnology, on governance and public management. Based on this example, it argues, i.a., that techno-economic paradigms do come with their own optimal (and less optimal) forms of governance and indeed public management, but that both the attitude towards the state and thus public management and the need for good public policy and its institutional prerequisites are a matter of the period within the paradigm, not of the paradigm itself.
\end{abstract}

\section{Task and background}

The final paragraph of the call for TED3 stated:

In its last segment, TED3 will discuss the possible impact of nonICT technology on Public Management and its reform, especially of new emerging bio- and nano-technologies. How might - although this is highly speculative - future technologies impact $P A / P M$ ? What are the optimal PA/PM structures for supporting the development of future technologies? The focus on these future technologies will also allow us to look at ICT in context, because it implies 'post-ICT' times. It will also enable us to discuss more clearly the relationship of technology and (the PA/PM aspect of) governance, and particularly of mutual interdependence and indeed dependence, thereby going back to the key elements of the ICT-PA-debate. 
The current essay tries to do so - contrary and at the same time complementarily to Christopher Pollitt's all-encompassing conceptual framework for studying the relation of technological change and public service management (2010), by setting out to investigate the impact both of a specific technology, nanotechnology (as one of the possible paradigm-setting post-ICT technologies), on governance and public management (PM), and by doing so from the perspective of a specific theory, Carlota Perez' Techno-Economic Paradigms (TEPs). ${ }^{1}$ It will argue that those paradigms come with their own optimal (and less optimal) forms of governance and indeed PM. ${ }^{2}$ Such an approach potentially provides a broad framework for understanding the relationship of technology and PM, and it may also highlight some of the counter-intuitive impacts of technological change on PM and of the need for a wider, multi-disciplinary approach. (And as all projections into the future, it may also serve to elucidate the present, more specifically the current ICT paradigm and its importance for PM.)

Perez herself builds on Kondratieff (see 1926), Schumpeter (see 1924, 1939) and Freeman (see Freeman and Louçã 2001), forming what Brian Arthur has called "the Schumpeter-Perez-Freeman story." (2002) $)^{3}$ Thus, this is a theory which - in spite of substantial differences - hails from the context of Long Waves, which are generally controversial and, in the context of some economics paradigms, unverifiable, but which are one foundation of innovation theory and innovation economics, particularly of the Schumpeterian kind. ${ }^{4}$ The theory is introduced here as the framework for discussing a mutually recognized problem (the connection of technological change, especially future technologies, on the one hand and governance and public management on the other), not as a truth of which one would have to convince the skeptics. The use of this theory in the current context is therefore primarily heuristic, i.e. not to argue that this is the only possible approach, nor to defend the theory as such, but I assume it to be both valid and helpful. ${ }^{5}$ Overall, this

1 Perez 2002, also 2007, 2006a, 2006b, 2004a, 2004b, Perez and Freeman 1988.

2 It could be said that the larger research context of the TEP approach is the thesis of the coevolution of technologies and institutions (cf. Nelson 1994), which would generally argue that the trajectories of PM are influenced both by explicit technological change and by more indirect impacts (such as on organizational structures, modes of production or networks) which may demand fundamental reconsideration of PM practices.

3 Arthur's recent attempt at a comprehensive theory of technology as such (2009) has not quite received the attention such an effort would seem to deserve.

4 That, too, is of course contested, but Schumpeter himself surely saw it this way; see McCraw 2007.

5 On the importance of the theory, which is i.a. a key basis of the European Union's Lisbon Strategy and of the corporate development strategy of IBM, see now comprehensively Drechsler, Kattel and Reinert 2009. 
essay is eventually a contribution to what Pollitt has called "Theories of Cycles or Alterations in Administrative Fashion" $(2008,51)$ based on technological change.

Simplifying I therefore assume with Carlota Perez that long-term economic development at first glance looks like the relentless progress of technology, but that it actually takes place in the form of overlapping surges, based on specific technological revolutions. ${ }^{6}$ There were five such revolutions, and five surges, in the last 250 years, and we are now in the middle of the fifth, namely the age of information technology, knowledge and global telecommunication (Perez 2002, 10-12, 14) - in brief, ICT (information and communication technology, sometimes also referred to as just IT) - which started in 1971.

[Next to] the new products, industries and technologies that characterize it, each technological revolution gives birth to a new set of generic all-purpose technologies and a new organizational common sense, or techno-economic paradigm, capable of modernizing all the existing economic activities. Thus, the entire economy is gradually brought to a higher productivity level (and not just the new industries). (Perez 2004b)

Technological revolutions change the 'commonsense' criteria for engineering and business behavior across the board. In fact, in my view, each technological revolution merits that name, not only for the importance of the new industries it ushers in and the new technical possibilities it opens but also - and perhaps mainly - because it radically modifies the 'best practice frontier' for all sectors of the economy. (Perez 2004a, 227.)

Not only the economy is transformed, however, but so are state and society. This is due to the more general nature of TEPs, for they generate "a set of best practice principles which serves as a conscious or unconscious paradigm for steering institutional change and for designing the social tools with which to master the new

6 These surges correspond to what is otherwise called cycles or (long) waves, i.e. they are a form of the Kondratieff waves. The specific term "surge" serves both to avoid the often unpleasant bickering about long waves and, more importantly, to underline the difference from them which consists primarily in a much broader perspective, including social and political elements, and in that we are not talking about waves in the general sense but about overlapping surges which break but do not "swing down"; Perez 2002, 23 FN 30, 60-67; on the difference between surge and wave, $2006 \mathrm{~b}$. 
techno-economic potential." (Perez 2004a, 217) "These principles can be said to conform to a techno-organizational paradigm."

And as a theory such as this is also intended to "help see ahead to the next phase of the sequence, in order to design timely actions to make the best of the impending opportunities" (Perez 2002, 7; see 163), one is also compelled to look beyond the end of the ICT paradigm and to speculate about the sixth surge and thus about the technology (or technology cluster) that will lead it. According to Perez, it "has often been suggested that biotechnology, bioelectronics and nanotechnology might conform the next technological revolution." She states that all these fields are developing; however, she purports that the "key breakthrough" is far from even being predictable. (Perez 2002, 13) Also, it is possible - as is often said - that the sixth surge might be governed by a convergence of bio- and nanotechnology, or a larger convergence that also includes ICT (regarding convergence, see only Roco und Bainbridge 2003) - and of course, it might just as well be none of the above.

As we are in the middle of the fifth TEP, probably - since the Fall of 2008 - at the "beginning of the end" of its turning-point, we can tentatively assume on account of the inner structure of the TEP that the next paradigm will make its breakthrough and begin to diffuse roughly by $2025-35$, not earlier.

\section{Nanotech as a TEP}

Nanotechnology is the creation of functional materials, devices, and systems through control of matter on the nanometer (1 to 100+ nm [one billionth of a meter]) length scale and the exploitation of novel properties and phenomena developed at that scale. A scientific and technical revolution has begun that is based upon the ability to systematically organize and manipulate matter on the nanometer length scale. ... nanotechnology actually represents a revolutionary super-field that will eventually become a foundation for such currently disparate areas as inks and dyes, protective coatings, medicines, electronics, energy storage and usage, structural materials, and many others that we cannot even anticipate. ... The new concepts of nanotechnology are so broad and pervasive, that they will influence every area of technology and science, in ways that are surely unpredictable. We are just now seeing the tip of the iceberg in terms of the benefits

7 Perez 2004a, 238; see 218, 223, 229, 236-238; 2002, 16-19, 24-25, 153; see also Gehlen 1970, 36, 76-77. Thus, the TEP model certainly is a form of technological determinism, albeit "in a mild form," Perez 2007; see generally in this context Smith und Marx 1994; also Dolata and Werle 2007, esp.9-104. The author of this paper is happy to diagnose some mild technological determinism for himself as well. 
that nanostructuring can bring. (Los Alamos National Laboratory 2004)

We are focusing on nanotechnology here because of its potential as the postICT paradigm-leading technology (and the purpose of the respective segment in TED3 is to go beyond ICT) and to reflect from there both upon ICT itself and upon technology and PM as such, especially because of - and not despite - the fact that nanotech and PM seem infinitely less related than ICT and PM. But what are the reasons for assuming that it is nanotechnology which will be the paradigm-leading technology in the sixth surge to begin with, rather than biotechnology or convergence? Cons include

1. the existence of alternatives such as the highly dynamic field of biotechnology and a placatory model of inclusive convergence so that it is by no means certain that nanotechnology will indeed "win the race";

2. the fact that before the big bang, it is always uncertain which technology will lead the next paradigm - in the 1960s and 1970s, as can be seen from the classical indicators, such as contemporaneous visions of the futures and science fiction, the designated next leading technology was nuclear power, not any kind of ICT;

3. the fact that according to Arnold Gehlen's philosophy of technology - which is not the foundation for Perez's theory, it is true, but which does seem to exhibit numerous parallels with it and to partially share its understanding of economy and society, and thus to provide an additional foundation to it (Gehlen 1970, 9) -, nanotechnology does not represent a further abstraction, a further disengagement from the human body, when compared to ICT, which means that in effect, it would not constitute logical progress. ${ }^{9}$

Arguments in favor of nanotechnology as the leading one of the next TEP include

1. the conceivability of nanotechnology as a paradigm, i.e. its potential to radically change and transform the Lebenswelt of mankind, not just the economy $;^{10}$

8 I hope to shed further light on the Gehlen-Perez relationship some time soon; for the time being, it must remain a mere assertion - one, however, that has been discussed with Perez (discussion of 27 September 2007).

9 According to Gehlen, the history of technology in the sense of "organ replacement" is a result of a growing movement away from the body, from the organic to the inorganic; 1970, 9-11.

10 Nano-scenarios that have been suggested by industry, governments or in the context of technology assessment (see e.g. the otherwise excellent Elsner 2009) are frequently rather restrained and thought out for a short-term scope; thus, they take the further potential of nanotechnology only into account to a limited degree. 
2. the unattractiveness of the alternatives: in effect, convergence is a "weasel word", evading the necessity to settle on one technology (and today rendering it possible to smuggle good old ICT into the new paradigm in a prominent or co-leading role, rather than as part of the infrastructure - a comfortable and comforting and thus tempting idea). Biotechnology, on the other hand, is much more limited than nanotechnology because in principle, any problem that can be solved by the former can also be handled with the latter - and a large amount of further problems on top of that (see, albeit with caution, Drexler 2007, Roco and Bainbridge 2003); ${ }^{11}$

3. the fact that the idea of nanotechnology as the leading technology is a realistic one, i.e. present solutions, patents, technologies, etc. make it seem possible from today's perspective (see most recently Elsner et al. 2009);

4. finally nanotechnology's potential of solving the problems of the fourth surge, the paradigm of mass production - namely the problems of material and energy (which could not be solved by the fifth wave) -, and also some of the problems of the fifth surge itself; for that reason, it represents logical progress. ${ }^{12}$

In sum, it may be said that the chances of nanotechnology indeed being the leading technology of the next TEP are fairly high, so that it at least seems sensible to focus on it and to ponder how to react to that scenario and what the consequences could be, from the perspectives of technology, economy and state and society.

\section{3. nanoGov}

This insight takes us to the main question of the current considerations at last, the connection of TEPs and governance (we will later get to PM; for a definition of governance, see Drechsler 2003). What could or should governance look like in the nano-paradigm, the sixth TEP, an era which only begins in 20-30 years? To ask such a question, to even suggest an answer for it, may strike one as frivolous from many a perspective, but in light of the TEP model, the question can be discussed at least in the realm of speculation.

What are the odds of nanotechnology influencing governance at all, even if it will indeed "take over" in a quarter of a century? According to the TEP model, the answer is that it is highly likely, for as we know, it is in the nature of the leading

11 The beginning of a TEP is always based on the preceding paradigm and develops from it, resulting in a kind of convergence; the important aspect regarding the new TEP, however, stems precisely from the specific elements of the leading technology, and the aspect of convergence rather makes it harder to recognize the latter. From today's perspective, it is hardly possible to envision a nano-paradigm without the enabling role of ICT. Perez herself, in fact, opts more for a convergence model (discussion of 30 November 2008).

12 See Perez and Freeman 1988, as suggested by Perez (discussion of 27 September 2007). 
technology to influence and shape organization per se, general best practices and processes - this has to carefully be set apart from characteristics which are specific to the respective phases and periods. The current ICT paradigm is the best example, not only, but also with respect to the catchphrase "e-Governance" (eGov); the situation was the same in the previous paradigm of mass production. Judging from the theoretical basis of TEPs, it would be impossible that there was no influence of this kind during the sixth surge.

What sort of influence could it be though? Taking up Gehlen's argument again, we can attribute to nanotechnology a return to the physical, for what is central here is substance, material, things, everything that belongs to the "real world", including the human body. This is precisely what ICT - and several theories from the ICT era - distanced itself from by overcoming space, privileging ideas and communication; the key word was frequently "virtuality" (an obsolete concept in 2010, when the - always imagined - walls between the "virtual" and the "real" worlds have very obviously crumbled). The randomness of space, substance, the body and its dwelling-place, all but defining to ICT, would be revoked or even supplanted in a paradigm that centers on matter and the body. This would speak for the formation of physical clustering of production as well as of life, for the necessity of gathering at specific places, and thus for matters of space and in effect their power, for bigger problems in the context of migration, demographic shifts, etc. ${ }^{13}$ The relevance of a governance structure which coordinates, balances but also conserves, in other words that of a classical state of an Aristotelian conception (Arist. Pol.), is thus likely to grow remarkably.

Is it necessary though to know today, or at least to think about, what governance might look like in the nano-paradigm? "No" appears to be the proper answer here for - apart from the lack of recognizability - no precautions must or can be taken right now for this distant age; there is no impact on today. It shall be said, however, that precisely because of the similarities with biotechnology, which also heavily focuses on the body, speculations regarding the nano-paradigm are certainly suitable at present to serve as a corrective for the absolutization of ICT - in other words, ICT also has an expiration date on it, at least as regards its dominant role. (cf. Drechsler 2002) This is all the more necessary because the difficulty even for those whose profession entails dealing with future, change, strategy and innovation, to imagine a world in which the net world, communication and information are not as important anymore as they are today is immense (important they surely will

13 In such a case, Carl Schmitt's philosophical philosophy, contested as it well may be, seems to offer itself as an appropriate tool to grasp the paradigm; cf. Drechsler 1997. 
remain). ${ }^{14}$ It is all the more difficult, perhaps almost impossible, for those aware that we are only at the beginning of the impact ICT will have, not only on governance and PM, but on people and their identities as such, in the years to come because of the truly radical transformation of human interaction caused by the Web 2.0 (for some good journalistic accounts, see Stone 2010; Rieger 2010; Schirrmacher 2009), which means that the proper focus on what was once eGov must today be on Facebook, Twitter, Google or Skype. (Castells 2009)

\section{The State and TEPs}

But how about the role of the state in the TEP model generally? The idea of governance is an ICT approach per se, i.e. an approach significantly inspired and shaped by the ideas of networks, communication and information (see Castells 2001, Drechsler 2005); thus, it might not be a permanent "acquisition" but rather a temporary phenomenon linked to the current paradigm. However, the following considerations are mainly concerned with government, in other words with the role of the state in its actual narrow sense (Drechsler 2003, 2004, 2005, and government persists within governance and remains relevant or even grows regarding its tasks. (Kattel 2004) In addition, it is always a central feature of a paradigm-leading technology that it achieves a political unity of the first, second and third sectors, i.e. classical governance, by influencing all of them in a significant way. So, the potential temporality of the phenomenon may be considered harmless for our purposes.

These thoughts direct our considerations towards the role of the state in the gestation period of the next paradigm during the deployment period of the current one, i.e. its phases of synergy and maturity, at the end of which the preparations for the next surge and, soon after, the big bang of the new leading technology occur. How does, or should, the role of the state look during this time?

It is highly relevant at this point to figure out which features belong to the paradigm, the period and the phase respectively. I would like to suggest that the regard in which the state and its power are held, the attitude towards the state and thus its power and standing - well beyond the state's engagement in the economy - and which I will call "state closeness" (i.e. closeness to the state, Staatsnähe, for current lack of a better word), both on account of empirical evidence and the inner logic of the model, is indeed a matter of the period, not the paradigm. In the installation period, there is "state distance" (Staatsferne) - there is general critique, indeed rejection of the state and its possibilities, which leads to a critique of the tasks of the state

14 Perez herself thus sees ICT as "likely to be the platform for a knowledge-based society for many decades to come" and "as 'manufacturing' was for the first four surges; the underlying logic of several sets of technologies of increasing complexity and going deeper into the dynamics of matter." (Discussion of 30 November 2008) 
and their reduction, or at least an attempt thereof -, while the deployment period is denoted by state closeness. (See Drechsler et al. 2006, 15-20)

As the following graph ${ }^{15}$ will show, I suggest that this is less so in the sense of stability but, as was to be expected, in a dynamic form. Contrary to the surges themselves, which as Perez has noted and indeed discovered are precisely not waves or cycles (Perez 2006b), the degree of state closeness seems, by way of a hypothesis that I herewith offer, to change in a fairly genuinely wavelike trajectory that shows a sharp decline during installation, an often swift reversal with the crash, and a steady but weakening ascent during deployment.

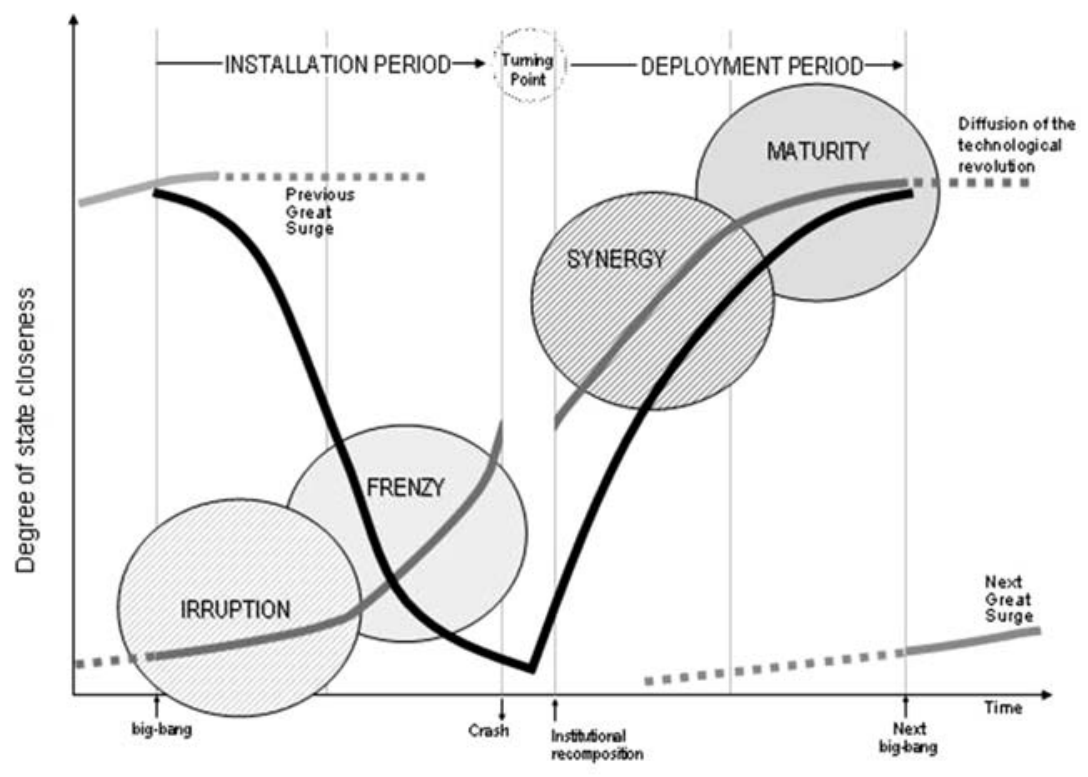

Of course, this graph is not "scientific" in the sense of empirical validation, nor of a precise denotation of the y-axis; it only expresses a certain dynamic that can be less quantified than experienced, as is appropriate for the TEP theory however, some further corroboration is surely required (and also intended). Most certainly, the curve will look differently in different surges, as well as in different countries (the present one is altogether based on the development in the core

15 Original graph supplied by Perez for Drechsler 2009b (23 November 2007), based on Perez 2002, 48, adapted by the author. Again adapted by the author for 2009a and adjusted after discussions with Perez (29-30 November 2008). (C) Carlota Perez 2002, 2007; this version (C Wolfgang Drechsler 2007, 2008. Perez herself did agree with the dynamics of the curve but sees a slightly different shape, especially longer plateaus of state closeness and more steep descents and particularly ascents (discussion of 1 December 2008). 
country or countries), and as always, its smoothness is only an ideal, but the general trajectory should hold if the hypothesis were to be judged as correct or at least heuristically useful.

The active, competent, appreciated state would actually be an obstacle in the period of installation, which is characterized by focusing on the economy (and new technology), being speculative and having almost an "anti-societal" stance and which must (both in the sense of "will" and "should") lead to a "faulty result", while state distance is needed in the frenzy phase both for phasing out the old leading technology and for supporting and establishing the new one.

Yet not only the end of the current paradigm requires the state in the sense of creative destruction management, ${ }^{16}$ but also - and this is a key aspect for the entire considerations regarding state closeness -, even especially, the implementation of the deployment period demands this, particularly in the non-economic realm, which for the most part is the foundation for whether the synergy phase really gives rise to a "golden" or merely a "gilded" age. (See Perez 2002, 53, 76, 167; 2007) Recent developments, unfortunately, seem to indicate that precisely this might be the case right now, partially because the current crisis was mastered "too well" by the state side both in Europe and the United States and thus only led to a temporary change of mind of the protagonists of the old mindset of Staatsferne; the upswing of the curve, in some respects, seems halted. (See Drechsler forthcoming; cf. Cassidy 2010)

Especially concerning the development of the new leading technology, howev$\mathrm{er}$, it is the state's responsibility not only to support but also to help shape it because hardly anything happens "just like that"; the market does not do so automatically. Some sort of risk socialization appears to be necessary if one does not want the new technology to pass one by, and economic, industrial and indeed innovation policy has always been the hallmark of the successful state (including, as we now would add, state-like organizations). (See Wade 2003; Reinert 1999; Rochet 2007.) Indeed, as has apparently been the case so far, every time a new paradigm is launched, the state's specific role is to reduce the risk that the state in question misses out on progress or that its position is not sufficiently suitable for the new phase. Because of the central importance - in the context of innovation and surges - of the reorientation of the national economy towards the new leading technology, any other outcome would mean falling behind, with all its dire consequences.

16 In the TEP model, creative destruction takes place both in the collapse before the turning-point and in the transition from one TEP to the next, i.e. roughly every 20-30 years; in different shapes, but in both instances as part of the installation period. 


\section{5. nanoPM}

What does this mean for the role of the state regarding nanotechnology? If, as I have argued, the odds that it will turn into the new leading technology are high, it must not be neglected, even now. The state's task now would be to make big investments in the sector (both research and development); of course, other sectors and other technologies (e.g. biotechnology) must also be kept in mind. It is relevant though that investments of this kind do take place, and especially in niches that the economy has shied away from (at least so far), i.e. investment in basic research on the one hand and in a range of products on the other that sound illusory and do not seem usable in any way - thus, by no means e.g. investment in paint and varnish or medicine, areas where a crowding-out effect could be expected. What is relevant here is precisely the possibility for the state not to let its behavior be governed by the urge to be lucrative, or rather: only lucrative in the long run, and that the state can shoulder a high risk level.

Investments which might have a larger effect on economic growth and employment in maybe 20-30 years can only be made if its timeframe is clear and if there are no expectations of faster extensive effects (and, as an aside, if the present focus is on the current TEP, namely ICT). (Perez 2006a) On the part of the state actors, three fundamental - and by no means new - qualities are again necessary, which were neglected or even disparaged in the context of state critique and state pessimism typical of the installation period that prevailed in the last few decades:

1. a long-term strategy, which also includes long-term perspective, employment and responsibility, according to the given timeframe;

2. a high level of competence among the actors, concerning both management abilities and the grasp of innovation and new technology;

3. the permission to make big mistakes and bad investments, for what is important is precisely the support for developments that might turn out to be dead ends otherwise, the state would not be needed.

Thus, to be adequately prepared for the nanotechnology paradigm, a state is required that employs a long-term perspective, has enough capacity at its disposal and tolerates mistakes. At this point, therefore, the question regarding nanotechnology and PM in the TEP context comes up, i.e. the question of which model of organizing PM is ideal for the establishment of nanotechnology (for instance, such as it were) as a TEP. As I have claimed previously (e.g. Drechsler 2009a; 2009b; Drechsler and Kattel 2009), among the options we have today, this clearly is the Neo-Weberian State (NWS) as conceived by Pollitt and Bouckaert. (2004, 96-102; see Pollitt et al. 2009) Taking up the positive elements of the New Public Management (NPM) but on a Weberian foundation, so that both are asymmetrically aufgehoben, the NWS reaffirms "the role of the state as the main facilitator of solutions to the new problems 
of globalization, technological change, shifting demographics, and environmental threat ... [and] the idea of a public service with a distinct status, culture, and terms and conditions." (Pollitt and Bouckaert 2004, 99) The NWS thus can reintroduce precisely the features of long-term thinking, administrative capacity and tolerance for mistakes to a PM that was crushed into expensive agony by the NPM, which was exactly the kind of PM theory matching the Zeitgeist of the installation period and its Staatsferne - suitable, perhaps, then; certainly obsolete today.

Since the NWS was the topic of TED1 (see Pollitt et al. 2009 and, in it, Drechsler and Kattel 2009), I will refrain from going into further details here. (I have summed up the NWS most recently in Drechsler 2009b and 2009c), I will just point out two things: First, it is interesting that in the field of PM and its scholarship - internationally and specifically in Europe - a reorientation away from the NPM and towards the NWS was already taking place slightly before the crash, as TED1, which as it seems was the first high-level conference dedicated to the concept, took place in January-February 2008, when there was only some faint writing on the wall. ${ }^{17}$ Thus, it was already in the turning-point itself that the PM perspective changes from the state distance characteristic of the installation period to the state closeness of the deployment period; the forms of the last paradigm are not simply replicated, however, instead they are reshaped, also particularly by components supported or even rendered possible by the leading technology of the current paradigm, ICT, such as complex civil involvement in processes of decision and control.

At this point, it might be worth reiterating, secondly, that eGov (or iGov or however it will turn out to be called in the decades to come) is a function of the ICT paradigm, not the period and thus independent of the question regarding state closeness or distance. NPM was specifically not unique to ICT, but intrinsic to installation periods; e-governance is in no way, empirical or other, related to NPM. (See Dunleavy et al. 2005, 2006) Hardly any categories, even the Weberian ones, are rendered obsolete by ICT (potentially that of exclusive employment, which is more of a problem in core areas of civil service anyway), some - such as the written principle or the division of labor - are even enhanced or at least exhibit reverse processes, e.g. the principle of hierarchy, which is weakened by models of network organization on the one hand but which can only realize its full potential by means of ICT's possibilities of extreme control and coordination on the other. (Drechsler 2005) How the Web 2.0 will change that remains to be discussed and to be experienced.

17 On the NWS as the most suitable PM model for the current times of crisis and the period thereafter, see Drechsler 2009c and, more generally, Drechsler forthcoming. 


\section{Conclusion}

In sum, while I hopefully have shown, based on the TEP theory, that a nanotechnology-dominated age will almost certainly lead to other forms of optimal PM than the ones we have today, those forms are too elusive for us to say much about them now. However, a push-pull effect can be detected from the perspective of the relationship between nanotechnology and governance regarding the path towards such an age: Nanotechnology requires a well-working state to establish itself appropriately; in return, it supports state closeness by its implicit demand for state competence, a long-term focus and tolerance for mistakes. The same can be said for all paradigmleading technologies, including biotechnology if it were to "win"18, and therefore in extenso for the role of the state, including PM, in the TEP model, which seems to be wave-like with the nadir in the turning-point and thus the zenith between the maturity of one and the irruption of the successive paradigm. If this were so, it would significantly add to our understanding of why the state and PM are evaluated differently at different times, and what the implications of this are. The significance of the paradigm shift for governance and PM also presents a further argument in favor of a sensible development towards the NWS at this moment. As to the question of TED3, "Public Management Reforms Now and in the Future: Does Technology Matter?", from the TEP perspective, the answer is an unqualified yes.

\section{Acknowledgments}

This essay is heavily based on Drechsler 2009a and 2009b. Research was partially funded by project no. 7577 of the Estonian Science Foundation ETF. For help with and feedback to this version, I am indebted to Erkki Karo and Christopher Stillings, as well as to the participants of TED3 in Ljubljana, especially Alan Rosenbaum, György Hajnal, Glenn Vancauwenberghe and Tino Schuppan.

\section{References}

Arthur, W. Brian. 2009. The Nature of Technology: What It Is and How It Evolves. New York: Free Press.

Arthur, W. Brian. 2002. "Is the Information Revolution Dead? If History is a Guide, it is not." Business 2.0, March 2002. Available at http://www.business2.com/ articles/mag/ 0,1640,37570,00.html (Accessed 15 November 2010).

18 Again, as was stated supra, there is not and cannot be conclusive agreement on what the next paradigm-leading technology will be, but the current analysis would also hold true when applied to biotechnology, which is likewise faced with similar challenges, both scientific and policy-related, that require extensive policy and administrative capacity on the part of the state; cf. most recently Rothmayr Allison 2009 (which I have not seen yet). 
Cassidy, John. 2010. "After the Blowup: Laissez-faire Economists do some SoulSearching - and Finger-Pointing." The New Yorker, 11 January, 28-33.

Castells, Manuel. 2009. Communication Power. New York: Oxford University Press.

Castells, Manuel. 2001. The Internet Galaxy: Reflections on the Internet, Business, and Society. New York: Oxford University Press.

Dolata, Ulrich and Raymund Werle (eds). 2007. Gesellschaft und die Macht der Technik. Sozioökonomischer und institutioneller Wandel durch Technisierung. Frankfurt/Main, New York: Campus.

Drechsler, Wolfgang. Forthcoming. "Public Administration in Times of Crisis." Keynote address, $18^{\text {th }}$ NISPAcee Annual Conference, Warsaw, Poland, 12 May 2010, to be published.

Drechsler, Wolfgang. 2009a. "Governance in and of Techno-Economic Paradigm Shifts: Considerations for and from the Nanotechnology Surge." In Wolfgang Drechsler, Rainer Kattel and Erik S. Reinert (eds). Techno-Economic Paradigms. Essays in Honour of Carlota Perez. London, New York: Anthem, 95-104, 410-412.

Drechsler, Wolfgang. 2009b. "NanoGov - Nanotechnologie, Innovation, Governance und Verwaltung aus der Perspektive der Techno-Ökonomischen Paradigmen." In Arno Scherzberg and Joachim Wendorff (eds). Nanotechnologie - Grundlagen, Anwendungen, Risiken, Regulierung. Berlin, New York: de Gruyter Recht, 307-325.

Drechsler, Wolfgang. 2009c. “The Rise and Demise of the New Public Management: Lessons and Opportunities for South East Europe." Uprava - Administration 7 (3), 7-27.

Drechsler, Wolfgang. 2005. "eGovernment and Public Management Reform.” Plenary lecture, eGovernance Catalonia Forum '05: "Public Administration in the age of the Internet." Barcelona, 13 June 2005. Available at http://www. gencat.net/forum-egovernance/2005/cat/ponencies.htm (Accessed 15 November 2010).

Drechsler, Wolfgang. 2004. "Governance, Good Governance, and Government: The Case for Estonian Administrative Capacity." Governance and Good Governance, Trames 8 (4), 388-396.

Drechsler, Wolfgang. 2003. "Good Governance." In Hanno Drechsler, Wolfgang Hilligen and Franz Neumann (eds). Gesellschaft und Staat. Lexikon der Politik. $10^{\text {th }}$ edn. München: Franz Vahlen (C. H. Beck). 
Drechsler, Wolfgang. 2002. "Darin Barney: Prometheus Wired: The Hope for Democracy in the Age of Network Technology, and Hubert L. Dreyfus: On the Internet." Philosophy in Review/Comptes Rendus Philosophiques 22 (2), 86-89.

Drechsler, Wolfgang. 1997. "Carl Schmitt: The Leviathan in the State Theory of Thomas Hobbes." Perspectives on Political Science 26 (2), 125-126.

Drechsler, Wolfgang and Rainer Kattel. 2009. "Conclusion: Towards the Neo-Weberian State? Perhaps, but Certainly adieu, NPM!” In Christopher Pollitt et al. (eds). A Distinctive European Model? The Neo-Weberian State. The NISPAcee Journal of Public Administration and Policy 1 (2), 95-99.

Drechsler, Wolfgang, Rainer Kattel and Erik S. Reinert (eds). 2009. Techno-Economic Paradigms. Essays in Honour of Carlota Perez. London, New York: Anthem.

Drechsler, Wolfgang et al. 2006. "Creative Destruction Management in Central and Eastern Europe: Meeting the Challenges of the Techno-Economic Paradigm Shift." In Tarmo Kalvet and Rainer Kattel (eds). Creative Destruction Management: Meeting the Challenges of the Techno-Economic Paradigm Shift. Tallinn: PRAXIS Center for Policy Studies, 15-30.

Drexler, K. Eric. 2007. Engines of Creation 2.0: The Coming Era of NanotechnologyUpdated and Expanded. WOWIO Books (www.wowio.com).

Elsner, Nils et al. 2009. Meta-Roadmap Nanomaterialien: Zukünftige Entwicklungen und Anwendungen. Düsseldorf: Zukünftige Technologien Consulting.

Freeman, Christopher and Francisco Louçã. 2001. As Time Goes By: From the Industrial Revolution to the Information Revolution. Oxford: Oxford University Press.

Gehlen, Arnold. 1970 [1957]. Die Seele im technischen Zeitalter: Sozialpsychologische Probleme in der industriellen Gesellschaft. Hamburg: Rowohlt.

Kattel, Rainer. 2004. "Governance of Innovation Policy: The Case of Estonia." Governance and Good Governance, Trames 8 (4), 397-418.

Kondratieff, Nikolai D. 1926. "Die langen Wellen der Konjunktur." Archiv für Sozialwissenschaft und Sozialpolitik 56 (3), 573-609.

Los Alamos National Laboratory. 2004. "What is Nanotechnology?" Nanoscience and Technology website. Available at http://www.lanl.gov/mst/nano/definition.html (Accessed 15 November 2010).

McCraw, Thomas K. 2007. Prophet of Innovation: Joseph Schumpeter and Creative Destruction. Cambridge, MA, London: Belknap (Harvard).

Nelson, Richard R. 1994. "The Co-evolution of Technology, Industrial Structure, and Supporting Institutions." Industrial and Corporate Change 2 (1), 47-63. 
Nordmann, Alfred, Joachim Schummer and Astrid Schwarz (eds). 2006. Nanotechnologien im Kontext: Philosophische, ethische und gesellschaftliche Perspektiven. Berlin: Akademische Verlagsgesellschaft.

Perez, Carlota. 2007. "Technological Revolutions, Paradigm Shifts, and Social Goals." The 2007 Marie Jahoda Annual Lecture, SPRU, University of Sussex, Brighton, October 2007 (ppt).

Perez, Carlota. 2006a. "Re-specialisation and the Deployment of the ICT Paradigm: An Essay on the Present Challenges of Globalization." In Ramon Compañó et al. (eds). The Future of the Information Society in Europe: Contributions to the Debate. [Sevilla:] IPTS, Luxembourg: OOPEC, EUR 22353 EN, 33-66.

Perez, Carlota. 2006b. "The Turning Point: An Open Stage for Socio-Political Choice." Lecture, $40^{\text {th }}$ Anniversary of the Research Policy Institute/CIRCLE, Lund University, Lund, September 2006 (ppt).

Perez, Carlota. 2004a. "Technological Revolutions, Paradigm Shifts and Socio-Institutional Change." In Erik S. Reinert (ed.). Globalization, Economic Development and Inequality: An Alternative Perspective. Cheltenham, Northampton, MA: Edward Elgar, 217-242.

Perez, Carlota. 2004b. "The Context for Innovation Policies and Strategies after the Financial Frenzy of the 1990s." Keynote address, $4^{\text {th }}$ European Forum for Innovative Enterprises, Stuttgart, 6 December 2004 (ppt).

Perez, Carlota. 2002. Technological Revolutions and Financial Capital: The Dynamics of Bubbles and Golden Ages, Cheltenham, Northampton, MA: Edward Elgar.

Perez, Carlota and Chris Freeman. 1988. "Structural Crises of Adjustment, Business Cycles and Investment Behaviour." In Giovanni Dosi et al. (eds). Technical Change and Economic Theory. London: Pinter, 38-66.

Pollitt, Christopher. 2010. "Technological Change and Public Service Management: Towards a Conceptual Framework." NISPAcee Journal of Public Administration and Policy 3 (2), 31-53.

Pollitt, Christopher. 2008. Time, Policy, Management: Governing with the Past. Oxford: Oxford University Press.

Pollitt, Christopher and Geert Bouckaert. 2004. Public Management Reform: A Comparative Analysis. $2^{\text {nd }}$ edn. Oxford: Oxford University Press.

Pollitt, Christopher et al. (eds). 2009. A Distinctive European Model? The Neo-Weberian State. The NISPAcee Journal of Public Administration and Policy 1 (2).

Reinert, Erik S. 1999. "The Role of the State in Economic Growth." Journal of Economic Studies 26 (4/5), 268-326.

Rieger, Frank. 2010. "Der Mensch wird zum Datensatz." Frankfurter Allgemeine Zeitung, 16 January. 
Rochet, Claude. 2007. L'innovation, une affaire d'état. Paris: L'Harmattan.

Roco, Mihail C. and William S. Bainbridge (eds). 2003. Converging Technologies for Improving Human Performance: Nanotechnology, Biotechnology, Information Technology and the Cognitive Science. Dordrecht: Kluwer.

Rothmayr Allison, Christine (ed.). 2009. The Impact of the Biotechnology Revolution on Comparative Policy Studies. Journal of Comparative Policy Analysis 11 (4).

Schirrmacher, Frank. 2009. Payback: Warum wir im Informationszeitalter gezwungen sind zu tun, was wir nicht tun wollen, und wie wir die Kontrolle über unser Denken zurückgewinnen. München: Blessing.

Schummer, Joachim and Davis Baird. 2006. Nanotechnology Challenges: Implications for Philosophy, Ethics and Society. Singapore: World Scientific.

Schumpeter, Joseph A. 1939. Business Cycles: A Theoretical, Historical, and Statistical Analysis of the Capitalist Process. New York, London: McGraw-Hill.

Schumpeter, Joseph [A.]. 1924. “The Instability of Capitalism." The Economic Journal 151, 361-386.

Smith, Merritt Roe and Leo Marx. 1994. Does Technology Drive History? The Dilemma of Technological Determinism. Cambridge, MA: MIT Press.

Stone, Brad. 2010. "The Children of Cyberspace: Old Fogies by their 20s." The New York Times, 10 January.

Wade, Robert. 2003. Governing the Market: Economic Theory and the Role of Government in East Asian Industrialization. Reprint. Princeton, NJ: Princeton University Press. 